\title{
Desafios contemporâneos para a antropologia no ciberespaço

\author{
O lugar da técnica
}

\author{
Contemporary challenges for Anthropology \\ in the cyberspace
}

The role of technique

Theophilos Rifiotis*

\begin{abstract}
Resumo: A antropologia no ciberespaço tem como ponto de partida a "comunicação mediada por computador", que, explicita ou implicitamente, pressupõe uma exterioridade dos objetos técnicos e reduz a agentividade apenas aos seres humanos. $\mathrm{O}$ presente trabalho procura refletir criticamente sobre tais pressupostos a partir de uma dupla inspiração teórico-metodológica: em primeiro lugar, tomando como referência a matriz clássica inaugurada por M. Mauss sobre a técnica nas "sociedades tradicionais" e analisando a especificidade atribuída à condição moderna com relação à técnica; num segundo momento e complementarmente, o texto avança no sentido de sistematizar os debates contemporâneos sobre agência e os limites da dicotomia humano/técnico, especialmente a partir das obras de B. Latour, notadamente a partir da noção de ciborgue. Trata-se, portanto, de uma releitura da perspectiva antropológica clássica da abordagem da técnica e o questionamento da noção moderna de objeto-técnico aplicado ao ciberespaço. Em última instância, colocamos em debate as noções de "uso", "apropriação" e "representação" dos objetos técnicos nos estudos antropológicos no ciberespaço.
\end{abstract}

Palavras-chave: cibercultura; teoria ator-rede; agência; redes sociotécnicas; hibridismo

Abstract: The starting point for anthropology in cyberspace is the idea of "communication mediated by the computer". Such an idea presupposes, explicitly or implicitly, a certain exteriority of the technical objects and, at the same time, it circumscribes agentive capacity exclusively to human beings. The present paper proposes a critical reflection about these assumptions by exploring a twofold theoretical and methodological inspiration. Firstly, it approaches the classical matrix about technique in "traditional societies", as it was first conceived by M. Mauss, as a reference

* Professor do Departamento de Antropologia, do Programa de Pós-graduação em Antropologia Social GrupCiber (Grupo de Pesquisa em Ciberantropologia), UFSC. <t.rifiotis@ufsc.br>

\begin{tabular}{|l|l|l|l|l|l|}
\hline Civitas & Porto Alegre & v. 12 & n. 3 & p. 566-578 & set.-dez. 2012 \\
\hline
\end{tabular}


and it analyses the specificity attributed to the modern condition regarding technique. In a second and complementary moment, the paper advances as it systematizes the contemporary debates about agency and explores the limits of the human/technical dichotomy. Here it dwells specifically on the works of B. Latour, and the notion of cyborg. It is thus a rereading of the classical anthropological perspective regarding the approach of technique and the questioning of the modern notion of object-technical as it is applied to cyberspace. Finally, the paper discusses notions such as "usage", "appropriation" and "representation" of technical objects in the anthropological studies in cyberspace.

Keywords: cyberculture; actor-network theory; agency; sociotechnical networks; hybridism

\section{Apresentação}

Que isso foi o que sempre me invocou, o senhor sabe: eu careço de que o bom seja bom e o ruim ruim, que dum lado esteja o preto e do outro o branco, que o feio fique bem apartado do bonito e a alegria longe da tristeza! Quero os todos pastos demarcados... Como é que posso com este mundo? A vida é ingrata no macio de si; mas transtraz a esperança mesmo do meio do fel do desespero. Ao que, este mundo é muito misturado... (Riobaldo).

G. RosA, Grandes sertões: veredas

Procuro no presente texto sistematizar algumas questões sobre as quais venho trabalhando nos últimos anos relacionadas ao hibridismo e agência não humana especialmente no campo da antropologia no ciberespaço. ${ }^{1}$ Para além de uma aparente novidade, tais questões têm se revelado estratégicas e motivo de embates dentro do campo antropológico e da comunicação, especialmente para os estudos da "cibercultura". ${ }^{2}$ Dentro dos limites dessa publicação,

Trabalho apresentado na $28^{\text {a }}$ Reunião Brasileira de Antropologia (São Paulo, julho de 2012).

2 Desde 1997, no GrupCiber (Grupo de Pesquisa em Ciberantropologia) do Programa de Pósgraduação em Antropologia Social da UFSC temos procurado desenvolver a pesquisa e a reflexão teórica no campo sociotécnico. Pessoalmente, tenho defendido a importância desses debates em todos os Simpósios da Associação Brasileira de Pesquisadores em Cibercultura (ABCiber) desde 2008, colocando em perspectiva o lugar da técnica na antropologia e repensando as noções de rede e técnica. Especialmente a partir dos Simpósios de 2010 e 2011, em que houve atividades que tomaram a teoria ator-rede como referência central para os debates. Delas participaram renomados pesquisadoras da área como André Lemos, Lúcia Santaella, Erick Felinto, Mássimo de Felice e Fernanda Bruno.

Registro desde logo que considero a noção de "cibercultura" como problemática e defendendo que deveríamos "[...] ao invés de definições apriorísticas de ciberespaço, cibercultura, etc., que poderiam se confundir com um nominalismo, retomamos as interrogações básicas sobre como se dão as interações nesse espaço. Possibilitando, então, condições para revisitarmos criticamente os conceitos e princípios metodológicos da Antropologia" (Rifiotis, 2002, p. 3). 
apresento uma breve discussão dos principais argumentos que tenho defendido no campo e seus desdobramentos.

Tomarei como foco analítico uma releitura da perspectiva antropológica clássica da abordagem da técnica e o questionamento da noção moderna de objeto-técnico. Concretamente, defenderei uma posição crítica em relação a noções correntes no campo da "cibercultura" tais como "uso", "apropriação" e "representação" envolvendo os objetos técnicos.

Lembro que as questões que serão mais adiante levantadas são resultantes de diferentes influxos e estão longe de poderem ser consideradas uma "novidade" para a antropologia. ${ }^{3}$ De fato, na minha perspectiva, desde o final dos anos 1980, e marcadamente desde o início dos anos 1990, observa-se um significativo esforço para pensar questões críticas tais como a relação sujeitoobjeto, natureza-cultura e sociedade-técnica. Elas são fundamentais para o enfrentamento dos horizontes antropológicos da "cibercultura", sobretudo, na discussão sobre o lugar da técnica. Podemos citar diversos textos da maior relevância como os de Bruno Latour "Une sociologie sans objets? Remarques sur l'interobjectivité" (1994) ou o mais conhecido deles "Jamais fomos modernos" (1994), publicado inicialmente em 1991. No campo específico da chamada "cibercultura" é digno de nota o esforço de Arturo Escobar em "Welcome to cyberia. Notes on the Anthropology of Cyberculture" (1994), publicado na prestigiosa Current Anthropology com comentários interessantes, dentre os quais destacaria os de Marilyn Strathern pelas suas contribuições na revisão crítica da antropologia. Porém, o trabalho mais emblemático e radical daquele momento foi publicado originalmente em 1991 por Donna Haraway e intitulado Manifesto ciborgue: ciência, tecnologia e feminismo-socialista no final do século $X X$ (2000). A leitura desses trabalhos continua atual e pode nos auxiliar na definição dos rumos da pesquisa antropológica da "cibercultura", especialmente na vertente da Teoria Ator Rede.

Foi inspirado pela Teoria Ator Rede, sistematizada por Latour em Reensamblar el social (2008), que venho refletindo sobre o que chamaria de hiato entre o estudo da técnica e dos objetos nas "sociedades tradicionais" e "modernas", e a necessidade de uma simetrização que nos possibilite perceber e pensar a técnica e os objetos para além da sua aparente exterioridade e limites dados pelo estreito perímetro do "uso", "apropriação" e "representação". É numa perspectiva sociotécnica que procurarei desenvolver meus argumentos sobre o hibridismo e a agência não humana.

A reflexão crítica que estou propondo tem como âncora os trabalhos desenvolvidos pelo GrupCiber do PPGAS/UFSC e é devedor dos diálogos, argumentos e pesquisas desenvolvidas em parceria principalmente com Maria Elisa Máximo e Jean Segata. 


\section{Um clássico moderno}

Marcel Mauss pode parecer uma referência secundária nos debates sobre a técnica. Podemos resgatar a sua contribuição para o campo da técnica diretamente do clássico "As Técnicas corporais" (1974, v. 2). Num sentido direto da sua própria definição de técnicas corporais: “[...] as maneiras como os homens, sociedade por sociedade e maneira tradicional, sabem servir-se de seus corpos" (1974, v. 2, p. 211). Dessa definição preliminar, Mauss tira consequências importantes para os estudos antropológicos, dos quais ele mesmo se diz insatisfeito, voltando-se para uma reflexão sobre a ideia de que há técnica quando há instrumento, para chegar a uma segunda definição que o leva a uma equivalência surpreendente: "O corpo é o primeiro instrumento e o mais natural instrumento do homem. O mais exatamente, sem falar de instrumento, o primeiro e mais natural objeto técnico, e ao mesmo tempo meio técnico do homem é seu corpo" (Mauss, 1974, v. 2, p. 217).

Sabemos hoje a importância dos estudos sobre corporalidade (Maluf, 2001), mas o lugar da técnica não tem sido explorado de modo sistemático. Os objetos manipuláveis que estão em vínculo intrínseco e permanente com o corpo (articulações, contatos), fazem do corpo e da chamada "cultura material" um conjunto integrado e indissociável, desde a publicação de "As Técnicas Corporais", pelo menos esse é o ponto de vista defendido por um grupo fundado em 1995 e que procura resgatar essa contribuição de Marcel Mauss (Rede, 2003). Lembramos que em 2010 foi publicada uma seleção de artigos da revista Technique \& Culture, em dois volumes, contendo artigos publicados na revista desde 1976, e que na nova edição cada autor comenta seus artigos. Naquela publicação fica evidente o interesse pela abordagem de Mauss e Leroi-Gourham sobre a técnica e sua hibridização do social, política, crença, metafísica, "cultura material", e aponta uma vocação que se reatualiza no estudo da técnica e dos objetos na antropologia. Como citada à primeira página do primeiro volume da reedição de Technique \& Culture: "Paradoxalmente, rien ne change peut-être plus vite que les techniques, rien ne change peut-être plus lentement que les idées, que les façons de penser" (2010, p. 6). Embora o tom possa parecer exagerado e polêmico, ele nos instiga a pensar os limites dos nossos trabalhos no campo da "cibercultura".

Retomando a questão inicial, diria que é evidente que o próprio Mauss dedicou-se com maior ênfase ao corpo, afastando-se dos objetos e dos instrumentos, mas a conexão estava feita e trata-se de uma espécie de anterioridade do corpo em relação aos outros instrumentos: 
Trata-se de uma ênfase consciente e que acarreta algumas consequências importantes. O objetivo de Mauss era lançar luz sobre um domínio até então oculto pela noção tradicional de tecnologia: em geral, diz ele, considera-se equivocadamente que existe tecnologia quando um instrumento é envolvido no ato de manipulação. A esta 'technique à instrument', Mauss opõe um conjunto de 'techniques du corps', às quais confere mesmo um papel preliminar: o corpo é o primeiro instrumento a dominar, aquele que intermedeia a relação com todos os demais (Rede, 2003, p. 283).

Vale ainda lembrar que para Mauss a análise antropológica é antes de tudo baseada no "fato social total":

Os fatos que nos interessam não são fatos especiais de tal ou qual parte da mentalidade; são fatos de uma ordem muito mais complexa, a mais complexa que se possa imaginar. São aqueles para os quais proponho a denominação de fenômenos da totalidade, em que não apenas o grupo toma parte, como ainda, pelo grupo, todas as personalidades, todos os indivíduos na sua integridade moral, social e mental e, sobretudo, corporal ou material (Mauss, 1974, v. 1, p. 198).

Claro está que Mauss aponta horizontes, inspira, à moda de um "mago", em contraste com Émile Durkheim (Fournier, 2003), ou da sua "etnografia surrealista", como nos aprendeu James Clifford (1998), que ele nos dá os termos conceituais para a nossa reflexão sobre a técnica. Mas está pontuado o aspecto específico da totalidade, num certo sentido, mais integrativa à qual devemos fazer face quando estudamos a técnica. E ela não foi a primeira, ao modo inspirador, próprio da produção de Mauss, ele já havia sinalizado no seu Manuel d'Ethnographie: “L'objet est dans bien des cas la preuve du fait social : un catalogue de charmes [objeto ou ação que exerce efeito mágico] est un des meilleurs moyens pour dresser un catalogue de rites" (Mauss, 1967, p. 7).

A utilização da palavra "charme" no sentido antigo de fetiche é bastante reveladora para o nosso debate porque restitui o lugar do objeto numa plenitude, ou totalidade, Mauss torna o objeto uma prova do fato social. ${ }^{4} \mathrm{O}$ social tornado matéria. Portanto, entendo que tratar os objetos técnicos em termos de uma pretensa exterioridade como é pressuposto nas noções de "uso", "apropriação" e "representação" é limitar os debates e as consequências da conexão entre o sujeito e o objeto já anunciadas por Marcel Mauss.

4 Complementarmente, a partir dessa citação poderíamos fazer uma associação com os fetiches, expressão cunhada por Bruno Latour (2002) para afirmar a combinação de fato com fetiche, e que mereceria um desenvolvimento específico. 


\section{Uma continuidade crítica}

Confiante na perspectiva aberta pela própria antropologia, Bruno Latour inicia suas reflexões em Jamais fomos modernos lembrando exatamente o que chamei aqui de hiato da antropologia. Para ele, as questões críticas da modernidade não se reduzem ao processo de purificação, pois se trata de um processo sempre acompanhado de seu oposto, a tradução. Se o primeiro funciona por simplificação e redução, o segundo é proliferação de híbridos. "Será nossa culpa se as redes são ao mesmo tempo reais como a natureza, narradas como discurso, coletivas como a sociedade?, pergunta-se Bruno Latour (1994, p. 12) apontando os limites e dilemas da modernidade.

Frente às redes sociotécnicas, somos muitas vezes interpelados pela justaposição do social ao técnico. Tratando-os de modo separado, purificado, pensamos em duas entidades e tratamos de procurar os melhores meios para recolocá-las em aproximação. Porém, a questão é: conseguiremos restituir o amálgama que foi perdido? É exatamente nesse sentido que a antropologia traria uma resposta aos dilemas produzidos pela segmentação e purificação, citando Latour:

Este dilema permaneceria sem solução caso a antropologia não nos houvesse acostumando, há muito tempo, a tratar sem crise e sem crítica o tecido inteiriço das naturezas-culturas. [...] Basta enviá-lo (o etnógrafo) aos arapesh ou achuar, aos coreanos ou chineses, e será possível uma mesma narrativa relacionando o céu, os ancestrais, a forma das casas, as culturas do inhame, de mandioca ou de arroz, os ritos de iniciação, as formas de governo e as cosmologias. Nem um só elemento que não seja ao mesmo tempo real, social e narrado (Latour, 1994, p. 12).

Acreditando que a antropologia já produziu um importante conjunto de trabalhos sobre a continuidade, a hibridização do humano e não-humano, não temos como deixar de interrogar o nosso próprio modo de pesquisar a "cibercultura". Fazendo uma autocrítica em 2008,5 eu já anunciava uma tomada de consciência do modo como vínhamos operando nas pesquisas do GrupCiber. ${ }^{6}$ Fiz a crítica das noções de "cibercultura", "comunidades virtuais", e o que chamo desde então de vontade de saber sociotécnico. Insisti na ideia

5 Comunicação apresentada na mesa-redonda "II Simpósio Nacional da ABCiber" (PUC/SP, 2008).

6 Um primeiro conjunto daqueles trabalhos encontra-se publicado no livro "Antropologia no Ciberespaço", organizado por Theophilos Rifiotis, Maria Elisa Máximo, Luciano Lacerda e Jean Segata, pela Editora da UFSC em 2010. 
de que a antropologia não tem fronteiras e que não há razão para operarmos na contemporaneidade de modo distinto do que operamos nas "sociedades tradicionais".

Confesso que desde o início do meu interesse pelo campo da "cibercultura" incomodava-me a ideia de "comunicação mediada por computador" (CMC). A própria ideia de "mediador" parecia-me deslocada uma vez que tratávamos de comunicação/interação entre humanos e o computador/rede eram apenas intermediários, invisibilizados na maior parte do tempo nas nossas descrições, apenas presentes como suporte. Por vezes um mero intermediário, quase nunca problematizado, apenas um elemento do cenário onde ocorrem relações entre humanos. Em linhas gerais, diria que um "mediador" seria aquele que transforma que atua de modo positivo, interferindo no processo, enquanto um intermediário é como uma "caixa-preta", algo que apenas transporta. Havia, em minha opinião, uma invisibilidade dos meios, dos componentes eletrônicos, dispositivos computacionais, softwares, rede física, etc. Se fossemos coerentes com a perspectiva então adotada, deveríamos falar em "comunicação intermediada por computador". Estimulado por essa crítica, passei a refletir sobre os elementos técnicos da "CMC", na rede sociotécnica. Porém, fazia isso separando os elementos em categorias de humanos, com intencionalidade, volição, consciência, etc, sujeitos da ação que empregam para fins que eles próprios definem os objetos e instrumentos.

No campo dos estudos da "cibercultura", a vontade de saber sociotécnico está expressa nas descrições dos modos de "iniciação" ou "socialização" dos "usuários", e nas possibilidades que tais descrições abrem para a compreensão das modalidades de "apropriação" ou "representação", entre outras palavraschave correntes nos nossos trabalhos. É assim que a descrição da plataforma (sempre presente e com lugar de destaque) é entendida como uma apropriação pelos sujeitos. Poderia enumerar muitos outros aspectos, mas prefiro dizer que os identifiquei a todos eles nos trabalhos do GrupCiber, e que ela correspondia a realizar um duplo movimento: em primeiro lugar situar os elementos técnicos, tecnológicos e, num segundo momento tratar do social que tomaria vida naquele "contexto". Era uma etapa de análise técnica (rede da internet, software, etc.) à qual se justapunha o social, que, aliás, era o objetivo mesmo da pesquisa. ${ }^{7}$ Daí deriva a crítica que temos feito à "netgrafia" cujo detalhamento, para não estender-me demasiado aqui, remeto aos trabalhos publicados recentemente pelo GrupCiber (Rifiotis; Máximo; Cruz, 2009 e 2010;

Longe de um tecnocentrismo, mas também de uma sociologização, o que propomos aqui é desenhar a necessidade de superar tal condição e elaborar uma abordagem sociotécnica da cibercultura. 
Máximo; Rifiotis; Segata; Cruz; 2012), nos quais discutimos detalhadamente a questão da etnografia no ciberespaço, e numa outra publicação na qual fazemos uma ponte mais diretamente em diálogo com o presente texto (Rifiotis; Segata; Máximo; Cruz, 2011). Retomamos daquele texto apenas os aspectos centrais.

A partir de uma detalhada revisão do campo, afirmamos em "A etnografia como método: vigilância semântica e metodológica nas pesquisas no ciberespaço" (Máximo; Rifiotis; Segata; Cruz, 2012) que persistem os debates que mantém certas dualidades e justaposições, dentre as quais destacaria as seguintes:

1. online e do off-line;

2. técnico e social;

3. sujeito e objeto.

No meu entendimento, tais aspectos críticos participam de uma revisão da antropologia contemporânea e não podem ser considerados apenas problemas, digamos, locais dos estudos da "cibercultura". O fato de não haver uma solução global para todos esses e outros problemas identificados nas nossas pesquisas nos coloca numa situação limite, que nos impulsiona a uma avaliação de conjunto. A tarefa de criar uma tal visão de conjunto certamente será objeto de debates e disputas importantes, e sua resolução ainda parece distante. Porém, há pistas importantes sendo desenhadas deste o final da década de 1990, como disse no início do trabalho, e que ainda tem grande potencial nesse sentido.

Assim, seguindo a argumentação de M. Strathern, insistiria então na ideia de que a antropologia contemporânea opera criticamente com os termos "sociedade" e "cultura", que seriam epifenômenos, "metáforas úteis" e estruturantes do discurso científico, e que eles implicam em modos de pensar que traduzem uma metafísica, a nossa própria cultura, a cultura da antropologia. Ou como diz M.Strathern: "Nossas próprias metáforas refletem uma metafísica profundamente enraizada, com manifestações que emergem em todas as espécies de análises" (2006, p. 39). Tal metafísica, invisível na nossa prática de pesquisa, seleciona e organiza o que deve ser observado e relatado. Assim, defendi que conhecer os elementos de base dessa metafísica seria tomar consciência dos limites do nosso lugar de produtores de discursos e do lugar que ocupam nossos discursos frente a outros.

A questão que estou levantando é complexa e exige não apenas relativismo e pluralismo, em si mesmos também limitados, mas uma perspectiva analítica que supere os discursos das negatividades, procurando colocar-se para além (ou aquém) daquele que completa os termos faltantes nas conceituações e práticas dos sujeitos. Da mesma forma, voltaria a insistir na ideia de pensarmos as 
críticas sistematizadas por Latour em Reensamblar lo social: una introducción a la teoria del actor-red (2008). Fundamentalmente, destacaria em primeiro lugar a seguinte colocação que me parece fundamental:

Es cierto que, en la mayoría de las situaciones, recurrir a la sociología de lo social no sólo es razonable sino también indispensable, dado que ofrece una taquigrafía conveniente para designar todos los ingredientes ya aceptados en el reino del colectivo. [...] Pero en las situaciones en las que proliferan las innovaciones, en las que son inciertas las fronteras de los grupos, en las que fluctúa la variedad de entidades a considerar, la sociología de lo social ya no es capaz de rastrear las nuevas asociaciones de los actores (Latour, 2008, p. 26).

A clara referência a uma sociologia pós-social, no sentido de que não se trata de considerar o social como um domínio especial e no qual a agência é exclusivamente humana, em Latour não é uma espécie de proposta radical de abandono da sociologia ou da antropologia. Trata-se, antes, de uma convocatória para concentrarmos o foco na ação, e não nas figuras já préestabelecidas para a observação, e ele sublinha que isso seria especialmente relevante nas situações em que proliferam as inovações e onde as fronteiras entre os grupos se encontram desestabilizadas. Em outros termos, o programa adequado para tais situações seria o de rastrear associações dos atores, ou seja, seguir os atores (humanos e não-humanos), ou seja, a produção do social em ação.

Num certo sentido, Latour vem buscando consolidar a presença dos objetos e outros entes não humanos no mundo do social. É o que se poderia chamar de repovoar o social. Segundo ele, houve uma espécie de estreitamento do sentido do social, operado pela exclusão dos entes não-humanos. Essa perspectiva estava presente nos trabalhos de Latour desde os anos 1990, senão vejamos com o que ele escreve num artigo intitulado "Une sociologie sans objets? Remarques sur l'interobjectivité" (1994):

Contre les dieux, les marchandises, les biens de consommation, les objets d'art, elle [a sociologia] a repris l'ancienne admonestation des prophètes: 'Les idoles ont des yeux et ne voient pas, des bouches et ne parlent pas, des oreilles et n'entendent pas'. Quelque chose d'autre, d'après elle, vient animer ces corps sans vie, ces statues mortes: notre croyance, la vie sociale que nous projetons en eux. Les fétiches ne comptent pas en eux-mêmes. Ils ne sont rien que l'écran de nos projections. Pourtant, nous l'avons appris de Durkheim, ils ajoutent bien quelque chose à la société qui les manipule: l'objectivation (Latour, 1994). 
Essa "interobjetividade", opção em relação a uma "intersubjetividade", se bem entendi o propósito de Latour, seria uma volta aos objetos e ao que eles acrescentam ao humano: "Les objets font quelque chose,ils ne sont pas seulement les écrans ou les rétroprojecteurs de notre vie sociale" (ibid., p. 49). É a questão da agência que ele coloca e com a qual nos defrontamos com enorme dificuldade. A própria agência individual (humana) tem sido, e continua sendo um problema teórico central. Veja-se, por exemplo, os esforços de Sherry Ortner sistematizando as abordagens da teoria da práxis (1984). Podemos dizer que a questão está fechada? O que dizer então para uma mudança ainda mais radical: a possibilidade de agências não humanas?

Ao longo dos seus trabalhos, Bruno Latour nos fornece uma série de exemplos de situações em que deveríamos problematizar a agência de objetos. Seria inútil aqui detalhá-los, mas lembremos ao acaso uma pequena série deles: arma, controle remoto, lombada. Mas também o celular, o computador, ou ainda medicamentos, etc, etc. Não há uma lista exaustiva porque não se trata de atribuição de agência, muito menos de uma questão ontológica, mas de descrição/rastreamento de interações. O princípio está na distinção entre "mediador" e "intermediário", ou seja, como um elemento (humano ou não humano) incide no curso de uma ação. Por essa razão, estou lendo rastrear conexões como uma tarefa tipicamente antropológica. A ação é o foco da atenção e não as entidades pré-configuradas. Agência não é determinação ou escolha, mas resultado da descrição de uma ação, de um processo, ou melhor, de um fluxo da ação.

Falar em agência é apresentar uma ação e mostrar ou narrar os rastros observáveis. Em outros termos, em muito breves, diria que a questão estaria em perguntar-se de que modo algo/alguém incide no curso da ação de outro agente? Como se dá essa incidência? Assim, a rede não seria mais um produto já dado, nem um simples contexto para a ação. Nem vínculo ou ligação. Ela não atua de modo homogêneo, nem linear, ela pode tanto produzir aproximação, quanto distanciamento. Ela é metáfora, discurso, contexto, mediador, intermediário, dependendo em qual ação os agentes estão envolvidos.

\section{Considerações finais}

O que foi colocado aqui é um desenho feito com as linhas gerais do que temos trabalhado no GrupCiber/UFSC. Longe de ser um programa de pesquisa fechado, propomos compartilhar nossas inquietações, colocá-las em diálogo para consolidarmos um campo de pesquisa que nos permita exercitar uma antropologia contemporânea. Digo "contemporâneo" no 
sentido de G.Agamben: "Contemporain est celui qui reçoit en plein visage le faisceau de ténèbres qui provient de son temps" (2008, p. 22). Para Agamben, a contemporaneidade é uma relação singular com o seu próprio tempo, ao qual aderimos tomando distâncias. A primeira adesão está feita com a modernidade, o segundo movimento seria colocá-la como uma estética, a estética da objetividade, e fazer um movimento que nos permitam sair do círculo purificação-tradução. A teoria ator-rede fornece as pistas necessárias para tal distanciamento.

A pesquisa no campo da "cibercultura" terá muito a ganhar levando em consideração a teoria ator- rede. Podemos interrogar a própria prática etnográfica sobre os limites de produzir narrativas de agências humanas e não-humanas. E sobre a prática de rastreamento de associações e como destacar agências, ou identificar coletivos híbridos, mapear fluxos da ação e seus deslocamentos e controvérsias. Vejo no trabalho de Marilyn Strathern excelente exemplo de descrição etnográfica de fluxo e deslocamentos. Ela escreveu um artigo que mereceria a nossa particular atenção no campo da "cibercultura" intitulado "Cutting the network" (1996), no qual ela dá exemplos de como rastrear fluxos e trabalhar com associações inesperadas que ocorrem no curso da ação.

Para os limites do presente texto, apenas posso deixar registradas as minhas questões e um primeiro desenho dos meus argumentos. Entendo que a questão crítica da noção de "sociotécnico" é que seu valor epistemológico, com a superação de dicotomias, ainda está sendo desenhado.

Para finalizar gostaria de citar um texto de Julio Cortázar intitulado "Preâmbulo às instruções para dar corda no relógio", o qual me serviu de epígrafe na minha apresentação o II Simpósio da ABCiber (2008) e que me parece desenhar exatamente o que tenho como horizonte para a antropologia, especialmente, entre nós que nos dedicamos à "cibercultura". Afinal, se a minha avaliação está correta, estamos nos iniciando numa perspectiva que nos obriga a rever nossos próprios fundamentos:

Pense nisto: quando dão a você de presente um relógio estão dando um pequeno inferno enfeitado [...]. Não dão somente o relógio, muitas felicidades e esperamos que dure porque é de boa marca, suíço com âncora de rubis; não dão de presente somente esse miúdo quebra-pedras que você atará ao pulso e levará a passear. [...] Dão o medo de perdê-lo, de que seja roubado, de que possa cair no chão e se quebrar. Dão sua marca e a certeza de que é uma marca melhor do que as outras, dão o costume de comparar seu relógio aos outros relógios. Não dão um relógio, o presente é você, é a você que oferecem para o aniversário do relógio. 


\section{Referências}

AGAMBEN, G. Qu'est-ce que le contemporain? Paris: Rivages, 2008.

CLIFFORD, J. A experiência etnográfica. Antropologia e literatura no século XX. Rio de Janeiro: UFRJ, 1998.

ESCOBAR, Arturo. Welcome to Cyberia: notes on the anthropology of cyberculture. Current Anthropology, U.S.A., v. 35, n. 3, p. 211-231, june 1994.

FOURNIER, M. Para reescrever a biografia de Marcel Mauss... Revista Brasileira de Ciências Sociais, São Paulo, v. 18, n. 52, 2003.

HARAWAY, Donna. Manifesto ciborgue: ciência, tecnologia e feminismo-socialista no final do século XX. In: HARAWAY, D.; KUNZRU, H.; SILVA, T.T. (Orgs.). Antropologia do ciborgue. As vertigens do pós-humano. Belo Horizonte: Autêntica, 2000.

LATOUR, B. Une sociologie sans objets? Remarques sur l'interobjectivité. Revue Sociologie du travail, Paris, v. 34, n. 4, p. 587-607, 1994.

LATOUR, B. Jamais fomos modernos: ensaios de antropologia simétrica. Rio de Janeiro: Editora 34, 1994.

LATOUR, B. Reensamblar lo social: una introducción a la teoria del actor-red. Buenos Aires: Manantial, 2008.

LATOUR, B. Reflexão sobre o culto moderno dos deuses fe(i)tiches. Baurú: Edusc, 2002.

MALUF, S.W. Corpo e corporalidade nas culturas contemporâneas: abordagens antropológicas. Esboços, Revista do Programa de Pós-Graduação em História da UFSC, Florianópolis, v. 9, n. 9, 2001.

MAUSS, M. As relações reais e práticas entre a psicologia e a sociologia. In: MAUSS, M. Sociologia e Antropologia. São Paulo: EPU/Edusp, 1974. v. 1.

MAUSS, M. As técnicas corporais. In: MAUSS, M. Sociologia e Antropologia. São Paulo: EPU/Edusp, 1974 [1936]. v. 2.

MAUSS, M. Manuel d'ethnographie. Paris: Éditions sociales, 1967 [1926].

MAXIMO, M.E.; RIFIOTIS,T.; SEGATA, J.; CRUZ, F. A etnografia como método: vigilância semântica e metodológica nas pesquisas no ciberespaço. In: MALDONADO, A.E. et al. (Orgs.). Epistemologia, investigação e formação científica em comunicação. Rio do Sul: Unidavi, 2012.

ORTNER, S.B. Theory in anthropology since the Sixties. Comparative studies in society and history, Cambridge University Press, v. 26, n. 1, p. 126-166, 1984.

REDE, M. Estudos de cultura material: uma vertente francesa. Anais do Museu Paulista. São Paulo, v. 8, n. 9, (2000-2001). Editado em 2003.

RIFIOTIS, T. Antropologia do ciberespaço. Questões teórico-metodológicas sobre pesquisa de campo e modelos de sociabilidade. Antropologia em Primeira Mão, PPGAS/UFSC, Florianópolis, v. 51, 2002.

RIFIOTIS, T.; MÁXIMO, M.E.; CRUZ, F.G. Diálogos metodológicos entre antropología y comunicación en la investigación de las formas de apropiación de 
centros publico de acceso a la internet. In: FERNÁNDEZ, A.P.; MALDONADO, A.E. (Orgs.). Metodologías transformadoras: tejendola red em comunicación, educación, ciudadanía e integración en América Latina. Caracas: Fondo Editorial Cepap, Universidad Nacional Experimental Simón Rodrigues, 2009.

RIFIOTIS, T.; MÁXIMO, M. E.; CRUZ, F. G. Diálogos de frontera: volviendo a pensar en las redes socio-técnicas a partir de experiências etnográficas en lan houses. In: VELAREZO, A.P.; MALDONADO, A.E. (Orgs.). La investigación de la comunicación en América Latina. Quito: Fondo Editorial FACSO-UCE, 2010.

RIFIOTIS, T.; MÁXIMO, M.E.; LACERDA, J.; SEGATA, J. Antropologia no ciberespaço. Florianópolis: Edufsc, 2010.

RIFIOTIS, T; SEGATA, J.; MÁXIMO, M.E.; CRUZ, F. Redes sociotécnicas: hibridismos e multiplicidade de agências na pesquisa da cibercultura. In: MALDONADO, A. E.; BARRETO, V.S.; LACERDA, J.S. (Orgs.). Comunicação, educação e cidadania: saberes e vivências em teorias e pesquisa na América Latina. João Pessoa/Natal: Editora da UFPB/Editora UFRN, 2011.

STRATHERN, M. Cutting the Network. Journal of the Royal Anthropological Institute, London, v. 2, n. 3, 1996.

STRATHERN, M. O Gênero da dádiva. Problemas com as mulheres e problemas com a sociedade na Melanésia. Campinas: Editora Unicamp, 2006.

TECHNIQUES \& CULTURE, Paris, v. 1, n. 2, p. 54-55, 2010.

Data de recebimento: 29.08.2012

Data de aprovação: 08.10.2012 